\title{
Point-of-care C-reactive protein testing in Febrile Children in General Practice
}

$\underline{\text { Miriam Monteny }}^{\underline{1}}$, MD, Marjolein H. ten Brinke ${ }^{\underline{1}}$, MSc, Jocelyn van Brakel $^{\underline{1}}$, MSc,

$\underline{\text { Yolanda B. de Rijke }} \underline{\underline{2}}$, PhD, Marjolein Y. Berger $\underline{1}$, MD, PhD

${ }^{1}$ Department of General Practice, Erasmus MC, Rotterdam, The Netherlands

${ }^{2}$ Department of Clinical Chemistry, Erasmus MC - Sophia Children's Hospital,

Rotterdam, The Netherlands

Correspondence:

Marjolein Y. Berger, MD, PhD

Erasmus MC

Department of General Practice

Room Ff 322

PO Box 2040, 3000 CA Rotterdam, The Netherlands

Tel. 0031-10-4087631, fax. 0031-10-4089491

Email: m.berger@erasmusmc.nl

Running title: CRP POCT in febrile children in general practice 


\section{Abstract}

Background: Point-of-care testing for C-reactive protein (CRP) may be helpful in differentiating viral from bacterial infection. Such a device should give results comparable to laboratory testing. The aim was to evaluate two point-of-care CRP tests (Nycocard and QuikRead) in febrile children in general practice, compared to a reference immunoturbidimetric assay.

Methods: Cross-sectional study of febrile children aged 3 months to 6 years presented to a general practice out-of-hours service. Children were visited at home, where blood was taken for the tests, within 24 hours of presentation. The Nycocard test was performed at home, whereas the QuikRead and reference test were performed in the laboratory.

Results: 76 children were enrolled. All three CRP tests were performed in 59 children. The mean difference between the reference test and Nycocard and QuikRead was 0.6 $\mathrm{mg} / \mathrm{L}$ and $-6.1 \mathrm{mg} / \mathrm{L}$, respectively. The slopes of the Passing and Bablok regression were 0.95 (95\% CI 0.9-1.0) and 0.83 (95\% CI 0.81-0.85) for Nycocard and QuikRead, respectively.

Conclusion: Up to a concentration of $160 \mathrm{mg} / \mathrm{L}$ the Nycocard correlated well with the reference test, while the QuikRead underestimated concentrations above $60 \mathrm{mg} / \mathrm{L}$. The Nycocard test seems a good candidate for CRP point-of-care testing in general practice.

\section{Keywords}

Child; C-reactive protein; Family practice; Fever; Point-of-Care Systems

\section{List of Abbreviations}

SBI, serious bacterial infection; POCT, point-of-care testing; ICC, intraclass correlation coefficient 


\section{Introduction}

Fever is very common among children in general practice (1). Febrile children are often presented in the evening, outside normal office hours and are therefore mostly seen in general practice out-of-hours services. Fever generally has no serious consequences, but approximately $1 \%$ of children develop a serious bacterial infection (SBI), e.g. pneumonia or meningitis, with possible life-threatening complications $(2,3)$. Early recognition and treatment of SBI leads to a better prognosis $(4,5)$. Differentiating the few bacterial infections from the bulk of self-limiting viral infections in febrile children is a great challenge for general practitioners.

The use of near-patient or point-of-care testing (POCT) for C-reactive protein (CRP) measurement in general practice has the advantage of providing the result within minutes, making early diagnosis and management of bacterial infections possible. Such POCT devices should give results comparable to reference testing and be feasible to use in daily practice.

CRP is the first described acute phase protein, produced by hepatocytes as part of the non-specific acute phase response to infection, inflammation and tissue damage (6). CRP values in healthy individuals are below $10 \mathrm{mg} / \mathrm{L}$. After the onset of inflammation or tissue injury, CRP concentration increases rapidly in the first six hours, reaches maximal levels after approximately 48 hours and falls rapidly when stimulation ends. Therefore, CRP serves as a very useful marker in screening for infectious and inflammatory diseases as well as for monitoring the response to treatment or disease activity $(6,7)$.

The aim of this study was to evaluate two different POCT devices for CRP measurement, the Nycocard CRP and the QuikRead CRP, in febrile children presented to a general practice out-of-hours service. 


\section{Materials and methods}

\section{Patients}

Febrile children, aged three months to six years, presented at a general practice outof-hours service in Rotterdam on Monday to Thursday evenings were eligible for the study. Children were enrolled between March $7^{\text {th }}$ and May $31^{\text {st }}, 2005$.

The receptionist of the service questioned the parents about the fever of the child. The parents were informed about the study and were visited at home by a research assistant within 24 hours. During the home visit, the parents answered a structured questionnaire and the child was physically examined following a structured scheme. A finger prick in the middle finger was performed according to the NCCLS protocol (8). The obtained capillary blood was immediately used to perform the Nycocard CRP test. Another $400 \underline{\mu \mathrm{L}}$ of blood was drawn in heparin microtainers. Subsequently, the tubes were centrifuged and plasma was stored at $\underline{-20^{\circ} \mathrm{C}}$ until measurement.

Parents gave written informed consent. Children resisting physical examination or the finger prick were not enrolled. The Dutch Central Committee on Research involving Human Subjects (CCMO) approved the study.

\section{Primary outcome measure}

The primary outcome measure was the difference between the CRP value measured by the reference test and the POCT CRP tests, in $\mathrm{mg} / \mathrm{L}$.

\section{CRP tests}

For the Nycocard CRP test (Clindia Diagnostics, Leusden, the Netherlands) $5 \underline{\mu L}$ whole blood was taken to determine the CRP value in $\mathrm{mg} / \mathrm{L}$, using the Nycocard test kit. Two medical students performed all measurements. The medical students were trained by 
highly qualified laboratory technicians of the department of clinical chemistry during five sessions before performing the Nycocard CRP test in children.

The QuikRead CRP test (Orion Corporation, Orion Diagnostica, Espoo, Finland) has been evaluated on the QuikRead System for both whole blood (20 $\underline{\mu L})$ and plasma. In our evaluation protocol this CRP test was performed with plasma by trained laboratory technicians who were blinded for the results of the reference test, the Nycocard test and patient characteristics. $20 \underline{\mu \mathrm{L}}$ plasma was used to determine the CRP value in $\mathrm{mg} / \mathrm{L}$.

For the reference CRP test, the Tina-quant CRP Hitachi 912 (Roche Diagnostics, Penzberg, Germany) was used, which has been standardized against the CRM 470 (9). All plasma samples were analyzed in one batch after the enrollment period and laboratory technicians were blinded for the POCT CRP results.

\section{Patient characteristics}

Since the medical students were not blinded for patient characteristics, the Nycocard CRP results may be influenced by characteristics of the children such as gender, height of the fever, duration of fever at the moment of the CRP measurement, and an "illness score". This latter score is a measure of the first impression of the general condition or illness of the child. It is categorized into not ill, slightly ill, moderately ill and seriously ill. These characteristics were assessed during the home visit.

\section{Statistical analysis}

The linear association between the results given by the POCT CRP tests and the reference test was analyzed using Pearson's correlation coefficient. The agreement between the results was analyzed with the intraclass correlation coefficient (ICC). The ICC produces measures of agreement of values within cases and ranges from 0 to 1 . An ICC of 0.8 is accepted as a good agreement (10). 
The differences between the POCT CRP tests and the reference test were analyzed using the Bland and Altman method (11) and the Passing and Bablok regression (12). We considered the POCT CRP test clinically valid when results did not deviate more than 10 $\mathrm{mg} / \mathrm{L}$ from the results of the reference test in the concentration range of $0-70 \mathrm{mg} / \mathrm{L}$.

The non-parametrical Mann-Whitney test was used to test the relationship of the patient characteristics gender, body temperature, duration of fever and illness score, with the difference between the POCT CRP tests and the reference test. Body temperature was dichotomized at $\underline{38^{\circ} \mathrm{C}}$, duration of fever at 24 hours, and illness score at not ill versus ill (slightly, moderately and seriously ill).

Assuming an ICC of 0.9 a minimum of 46 individuals had to be included to reject the null hypothesis of ICC 0.8 with $\alpha \underline{=0.05}$ and a power of $80 \%$. 


\section{Results}

During the enrollment period 76 children were visited. In 15 children CRP values could not be measured by the reference test due to insufficient material. Main reasons for insufficient material were no consent for the finger prick and resistance of the child. The results of 61 and 59 children were analyzed for Nycocard CRP and QuikRead CRP measurement, respectively. Rectal temperature could not be measured in two children and temperature was measured axillary in another child.

Characteristics of the 76 enrolled children are presented in Table 1. The median age was 21 months (ranging from 3 to 71 months). The 61 children with full CRP data tended to be older, more often male and to have a longer duration of fever. The median height of the fever in these 61 children was $\underline{37.7^{\circ} \mathrm{C}}$ (ranging from 34.8 to $\underline{39.9^{\circ} \mathrm{C}}$ ) and did not differ from the children lacking reference CRP data.

\section{TABLE 1}

\section{Agreement}

The correlation coefficients of both CRP tests with the reference test were 0.99 . The overall ICC value as well as the ICC value in the concentration range of $0-70 \mathrm{mg} / \mathrm{L}$ was 0.99 for Nycocard, whereas both ICC values were 0.98 for QuikRead.

\section{Bland and Altman analysis}

The overall mean difference between the Nycocard CRP test and the reference test was $0.6 \mathrm{mg} / \mathrm{L}(\underline{\mathrm{n}=61} ; 2 \mathrm{SD} 19.7)$. In the concentration range of $0-70 \mathrm{mg} / \mathrm{L}$ the mean difference was $1.4 \mathrm{mg} / \mathrm{L}(\underline{\mathrm{n}=46} ; 2 \mathrm{SD} 11)$ and in the concentrations above $70 \mathrm{mg} / \mathrm{L}$ the mean difference was $-1.9 \mathrm{mg} / \mathrm{L}(\underline{\mathrm{n}=15} ; 2$ SD 35.4). The overall mean difference between 
the QuikRead test and the reference test was $-6.1 \mathrm{mg} / \mathrm{L}(\underline{\mathrm{n}=59} ; 2 \mathrm{SD} 31.3)$. In the concentration range $0-70 \mathrm{mg} / \mathrm{L}$ the mean difference was $-0.4 \mathrm{mg} / \mathrm{L}(\underline{\mathrm{n}=46} ; 2 \mathrm{SD} 11.8)$ and in the concentrations above $70 \mathrm{mg} / \mathrm{L}$ the mean difference was $-26.4 \mathrm{mg} / \mathrm{L}(\underline{\mathrm{n}}=13 ; 2$ SD 44). The Bland and Altman plots are presented in Figure 1.

Of the Nycocard results, $89 \%$ fell within $-10 \mathrm{mg} / \mathrm{L}$ or $+10 \mathrm{mg} / \mathrm{L}$ of the reference test results. In the concentration range of $0-70 \mathrm{mg} / \mathrm{L}$, the maximum difference was exceeded in 2 out of 46 results (4.3\%), by 14 and $24 \mathrm{mg} / \mathrm{L}$. Of the QuikRead results, $78 \%$ fell within $-10 \mathrm{mg} / \mathrm{L}$ or $+10 \mathrm{mg} / \mathrm{L}$ of the reference test results. In the concentration range of $0-70 \mathrm{mg} / \mathrm{L}$, the maximum difference was exceeded in 2 out of 46 results (4.3\%), by -15 and $-28 \mathrm{mg} / \mathrm{L}$.

FIGURE 1

\section{Passing and Bablok analysis}

The intercept of the Nycocard and reference test comparison was 2.3 (95\% CI 1.0-3.4) with a slope of 0.95 (95\% CI 0.9-1.0). The cusum test p-value was between 0.01 and 0.05. In the QuikRead and reference test comparison the intercept was 3.9 (95\% CI 3.3-4.6) with a slope of $0.83(95 \%$ CI $0.81-0.85)$. The cusum test $p$-value was $>0.1$. The plots are presented in Figure 2.

\section{FIGURE 2}




\section{Patient characteristics}

None of the patient characteristics gender, duration and height of fever and illness score was related to the differences between the reference test and the Nycocard test (pvalues $0.23-0.73)$. The distribution of CRP values for each of the three tests in the illness $\underline{\text { score categories not ill, slightly ill and ill (six moderately ill and one seriously ill) is }}$ presented in Figure 3.

\section{$\underline{\text { FIGURE } 3}$}




\section{Discussion}

In this study two CRP POCT devices for clinical use in febrile children in general practice were compared to a routinely used laboratory method. Overall the Nycocard CRP test correlated well with the reference test, while the QuikRead CRP test underestimated the reference test above the concentration of $60 \mathrm{mg} / \mathrm{L}$.

The Bland and Altman plot of the Nycocard test shows a good correlation with the reference test up to a CRP concentration of $160 \mathrm{mg} / \mathrm{L}$ with only three outliers, but a substantial increase in distribution with deviations of more than $10 \mathrm{mg} / \mathrm{L}$ above a concentration of around $200 \mathrm{mg} / \mathrm{L}$. The plot of the QuikRead test shows a smaller distribution up to a concentration of $60 \mathrm{mg} / \mathrm{L}$ compared to the Nycocard, but an increasing distribution above $40 \mathrm{mg} / \mathrm{L}$ with deviations of more than $10 \mathrm{mg} / \mathrm{L}$ above 60 mg/L. Furthermore, the Passing \& Bablok comparison shows a small constant bias in both tests, with a larger distribution in the lower concentration range for the Nycocard. However, the slope of the regression line of QuikRead indicates a proportional bias as well, indicating that the QuikRead deviation from the reference test increases with increasing CRP values, whereas the Nycocard deviation from the reference test is not dependent on the CRP values (up to $160 \mathrm{mg} / \mathrm{L}$ ).

Both tests show less precise measurement of CRP values in the higher concentration range. Most uncertainty in distinguishing viral from bacterial infection exists between CRP concentrations of 10 and $70 \mathrm{mg} / \mathrm{L}$ (13-15). A deviance in CRP concentration of 10 $\mathrm{mg} / \mathrm{L}$ of the reference test in this clinically relevant range may change the management of the febrile child (16), therefore the POCT device needs to correlate well in this concentration range. In the clinically relevant range the maximum difference was exceeded in only $4.3 \%$ in both tests. 
The Nycocard test produced higher values than the reference test, overall as well as in the case of outliers in the concentration range of $0-70 \mathrm{mg} / \mathrm{L}$. The QuikRead, however, produced increasingly lower values than the reference test above $40 \mathrm{mg} / \mathrm{L}$, which is in the clinically relevant range. Possible consequences of this imprecision in daily practice may be more unnecessary prescription of antibiotics and more hospital referral using the Nycocard, or missing children with bacterial infection using the QuikRead test. Randomized controlled trials are needed to evaluate the possible consequences.

Medical students performed the Nycocard test during home visits in general practice, whereas experienced personnel in the laboratory performed the QuikRead test. This could explain the larger distribution with Nycocard in the $0-70 \mathrm{mg} / \mathrm{L}$ range and this might indicate that QuikRead would perform less in daily practice. However, overall the QuikRead test would be expected to perform better in the laboratory by trained technicians compared to the Nycocard test performed at home.

The Nycocard CRP test can be carried out within 5 minutes using only $5 \underline{\mu L}$ whole blood, whereas the QuikRead test requires first a dilution of $20 \underline{\mu \mathrm{L}}$ whole blood with 1 $\underline{\mathrm{mL}}$ of buffer after which a blank measurement is needed. Although we did not evaluate the use of the QuikRead System at home, the use of Nycocard at home seems to be more feasible because fewer actions are needed.

The patient characteristics height and duration of fever, gender and ill score were not related to the difference between the Nycocard CRP value and the reference CRP value. Thus, when CRP measurement is performed on a POCT device by a general practitioner or assistant these variables do not seem to influence the results.

Our results were in accordance with the results of other studies with the Nycocard device. Most studies concluded that use of the Nycocard was acceptable for POCT (17- 
19). Our results for QuikRead were different from previous studies. We are aware of two studies evaluating QuikRead, one in general practice (20) and one in the emergency room setting (21). Seamark et al. tested the device in patients referred with a variety of conditions and found a mean difference of $1 \mathrm{mg} / \mathrm{L}$, with $95 \%$ of the POCT results within $\pm 10 \mathrm{mg} / \mathrm{L}$ of the mean value; the age of the patients is not given. Esposito et al. concluded that QuikRead and the standard reference assay showed similar median CRP levels and similar distribution of values. Both studies concluded that QuikRead performed reliably compared to a reference method. Taking into account the increasing underestimation of CRP values above $60 \mathrm{mg} / \mathrm{L}$ and the more labor-intensive method, we feel that, although not tested in daily practice, QuikRead is less suitable for CRP testing in general practice or an emergency room setting and more suitable for the laboratory setting.

The use of CRP as a diagnostic marker for SBI has been studied and debated extensively. Several studies indicate that an increased CRP concentration is related to a higher risk of SBI in febrile children $(14-16,22)$. However, the management of febrile children by the general practitioner should not be based only on a CRP value, but also on other grounds e.g. clinical presentation, duration of symptoms and medical history. $\underline{\text { Our }}$ results show that the elevation of CRP concentration tends to be higher and the distribution of CRP values to be more widespread among febrile children who appear ill compared to children who appear well. In order to determine the effect of CRP POCT on clinical decision-making, further large prospective studies are needed (23). In addition, $\underline{\text { high quality diagnostic studies are needed to clarify the added diagnostic value of CRP }}$ along with other variables in differentiating bacterial from viral infections. 
The use of POC CRP tests in general practice for early diagnosis and management of febrile children is promising. We feel that the Nycocard CRP test is a good candidate to meet this purpose. 


\section{Acknowledgements}

We greatly appreciate the contribution of the research assistants, the laboratory technicians of the Sophia Children's Hospital, and the general practice out-of-hours service Rotterdam-South.

Clindia Benelux BV, Leusden, The Netherlands and Mediphos Medical Supplies BV, Renkum, The Netherlands, provided CRP testing devices.

ZonMw (Dutch Organization for Health Research and Development), Programme Common Diseases funded this study. 


\section{References}

1. Bruijnzeels MA, Foets M, van der Wouden JC, van den Heuvel WJ, Prins A. Everyday symptoms in childhood: occurrence and general practitioner consultation rates. Br J Gen Pract 1998;48:880-4.

2. Okkes TM, Oskam SK, Lamberts H. Van klacht naar diagnose. Episodegegevens uit de huisartspraktijk. Bussum: Uitgeverij Coutinho, 1998.

3. Van den Bruel A, Bartholomeeusen S, Aertgeerts B, Truyers C, Buntinx F. Serious infections in children: an incidence study in family practice. BMC Fam Pract 2006;7:23. 4. Cartwright K, Reilly S, White D, Stuart J. Early treatment with parenteral penicillin in meningococcal disease. BMJ 1992;305:143-7.

5. Orellana P, Baquedano P, Rangarajan V, Zhao JH, Eng ND, Fettich J, et al. Relationship between acute pyelonephritis, renal scarring, and vesicoureteral reflux. Results of a coordinated research project. Pediatr Nephrol 2004;19:1122-6. 6. Pepys MB, Hirschfield GM. C-reactive protein: a critical update. J Clin Invest 2003;111:1805-12.

7. Clyne B, Olshaker JS. The C-reactive protein. J Emerg Med 1999;17:1019-25. 8. Clinical and Laboratory Standards Institute. Procedures and devices for the collection of diagnostic capillary blood specimens, 5th edn. Approved standard H4-A5. Wayne: NCCLS, 2004;24(21).

9. Baudner S, Bienvenu J, Blirup-Jensen S, Carlström A, Johnson AM, Ward AM, et al. The certification of a matrix reference material for immunochemical measurement of 14 human serum proteins. BCR Publication 92/92. Brussels: BCR, 1992:192pp. 10. Walter SD, Eliasziw M, Donner A. Sample size and optimal designs for reliability studies. Stat Med 1998;17:101-10. 
11. Bland JM, Altman DG. Statistical methods for assessing agreement between two methods of clinical measurement. Lancet 1986;1:307-10.

12. Passing H, Bablok W. A new biometrical procedure for testing the equality of measurements from two different analytical methods. Application of linear regression procedures for method comparison studies in clinical chemistry, Part I. J Clin Chem Clin Biochem 1983;21:709-20.

13. Gendrel D, Raymond J, Coste J, Moulin F, Lorrot M, Guerin S, et al. Comparison of procalcitonin with C-reactive protein, interleukin 6 and interferon-alpha for differentiation of bacterial vs. viral infections. Pediatr Infect Dis J 1999;18:875-81. 14. Pulliam PN, Attia MW, Cronan KM. C-reactive protein in febrile children 1 to 36 months of age with clinically undetectable serious bacterial infection. Pediatrics 2001;108:1275-9.

15. Galetto-Lacour A, Zamora SA, Gervaix A. Bedside procalcitonin and C-reactive protein tests in children with fever without localizing signs of infection seen in a referral center. Pediatrics 2003;112:1054-60.

16. Berger RM, Berger MY, van Steensel-Moll HA, Dzoljic-Danilovic G, DerksenLubsen G. A predictive model to estimate the risk of serious bacterial infections in febrile infants. Eur J Pediatr 1996;155:468-73.

17. Hobbs FD, Kenkre JE, Carter YH, Thorpe GH, Holder RL. Reliability and feasibility of a near patient test for C-reactive protein in primary care. Br J Gen Pract 1996;46:395$\underline{400}$.

18. Dahler-Eriksen BS, Lassen JF, Petersen PH, Lund ED, Lauritzen T, Brandslund I. Evaluation of a near-patient test for C-reactive protein used in daily routine in primary healthcare by use of difference plots. Clin Chem 1997:43:2064-75. 
19. Hjortdahl P, Landaas S, Urdal P, Steinbakk M, Fuglerud P, Nygaard B. C-reactive protein: a new rapid assay for managing infectious disease in primary health care. Scand J Prim Health Care 1991;9:3-10.

20. Seamark DA, Backhouse SN, Powell R. Field-testing and validation in a primary care setting of a point-of-care test for C-reactive protein. Ann Clin Biochem 2003;40:178-80. 21. Esposito S, Tremolati E, Begliatti E, Bosis S, Gualtieri L, Principi N. Evaluation of a rapid bedside test for the quantitative determination of C-reactive protein. Clin Chem Lab Med 2005;43:438-40.

22. Korppi M, Kroger L. C-reactive protein in viral and bacterial respiratory infection in children. Scand J Infect Dis 1993;25:207-13.

23. Delaney B, Wilson S, Fitzmaurice D, Hyde C, Hobbs R. Near-patient tests in primary care: setting the standards for evaluation. J Health Serv Res Policy 2000;5:37-41. 
Table 1: Characteristics of the 76 participating children, of whom 61 had full CRP data and 15 lacked reference CRP data

\begin{tabular}{|c|c|c|}
\hline Characteristics & $\begin{array}{l}\text { Children with full } \\
\text { CRP data } \\
\underline{\mathrm{n}=61}\end{array}$ & $\begin{array}{l}\text { Children lacking } \\
\text { reference CRP data } \\
\underline{\mathrm{n}=15}\end{array}$ \\
\hline Median age in months (range) & $21 \quad(\underline{4-71)}$ & $14 \quad(\underline{3-49})$ \\
\hline Median height of fever in ${ }^{\circ} \mathrm{C}$ (range) & $37.7(\underline{34.8-39.9})$ & $37.6(\underline{36.4-39.8})$ \\
\hline \multirow[t]{2}{*}{ Median duration of fever in hours (range) } & $48 \quad(12-186)$ & $24 \quad(12-84)$ \\
\hline & $\underline{\mathrm{n}} \quad(\%)$ & $\underline{\mathrm{n}} \quad(\%)$ \\
\hline Male gender & $37(61 \%)$ & $4 \quad(27 \%)$ \\
\hline Illness score 0 (not ill) & $18 \quad(29.5 \%)$ & $7 \quad(46.7 \%)$ \\
\hline Illness score I (slightly ill) & $36(59 \%)$ & $7 \quad(46.7 \%)$ \\
\hline Illness score II (moderately ill) & $6 \quad(9.8 \%)$ & $1 \quad(6.6 \%)$ \\
\hline Illness score III (seriously ill) & $1 \quad(1.6 \%)$ & $0 \quad(0 \%)$ \\
\hline
\end{tabular}




\section{Figure Legends}

Figure 1A: Bland \& Altman plot of the CRP concentration measured with the Nycocard and the reference test.

Figure 1B: Bland \& Altman plot of the CRP concentration measured with the QuikRead and the reference test.

Figure 2A: Passing \& Bablok regression plot of the Nycocard and the reference test.

Figure 2B: Passing \& Bablok regression plot of the QuikRead and the reference test.

Figure 3: Distribution of CRP concentrations for each CRP test in the three categories not ill, slightly ill and ill (median, interquartile range, min-max). 
Figure 1A

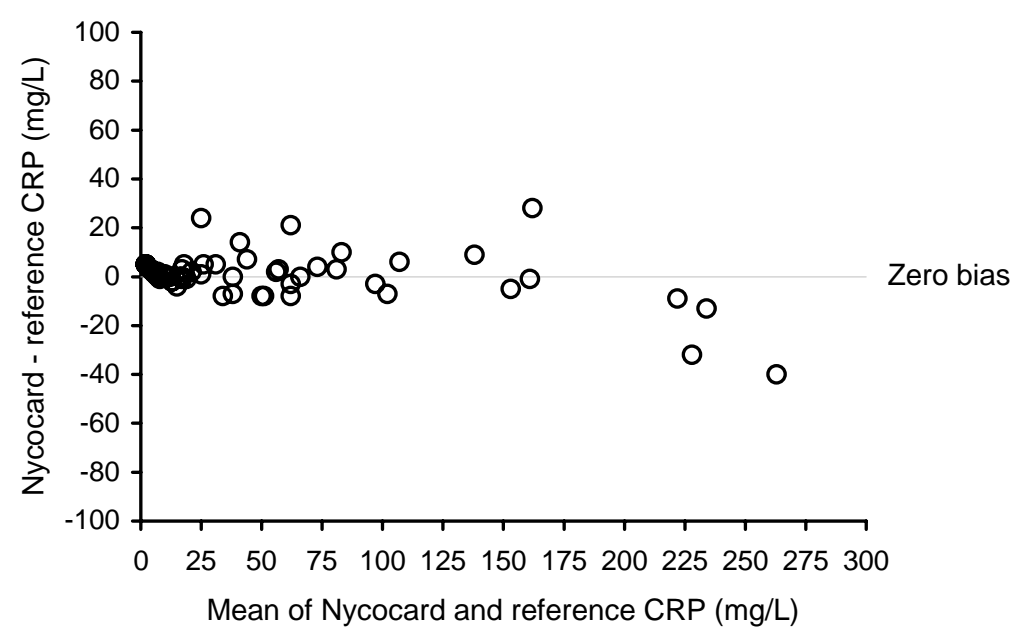

\section{Figure 1B}

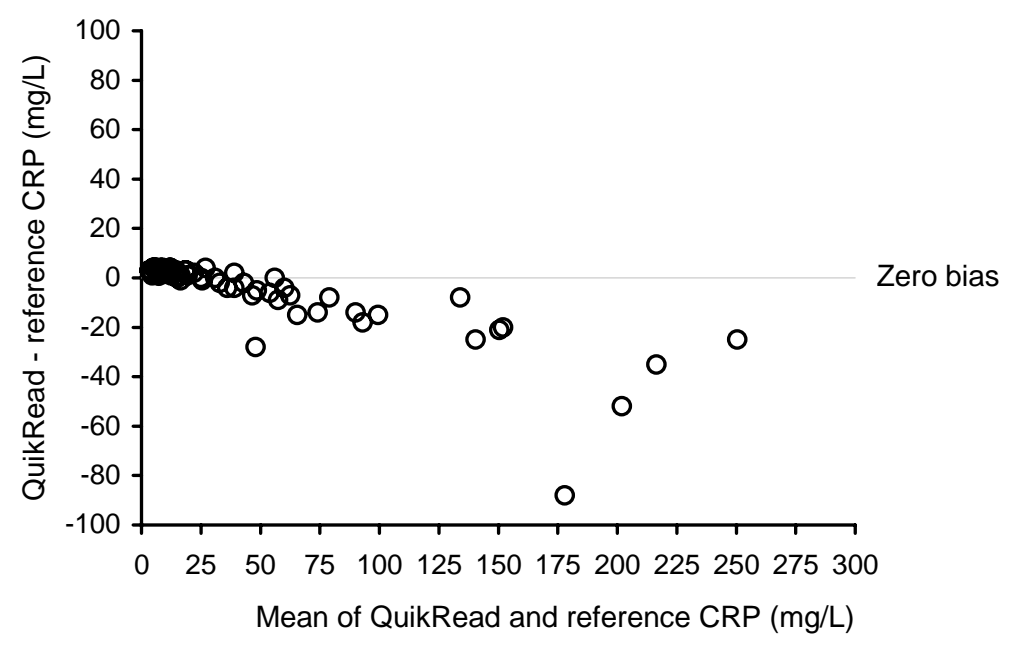


Figure 2A

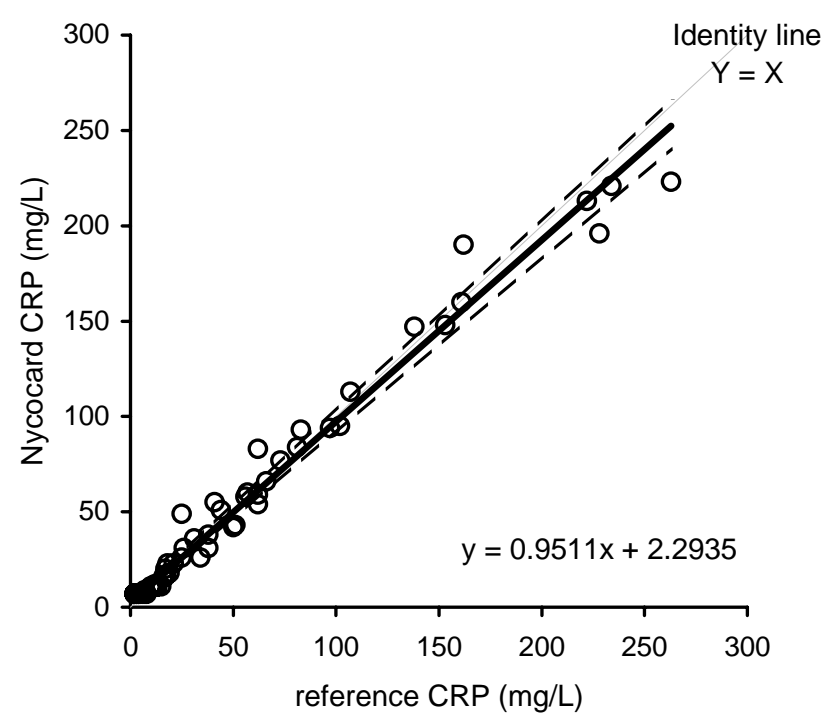

Figure 2B

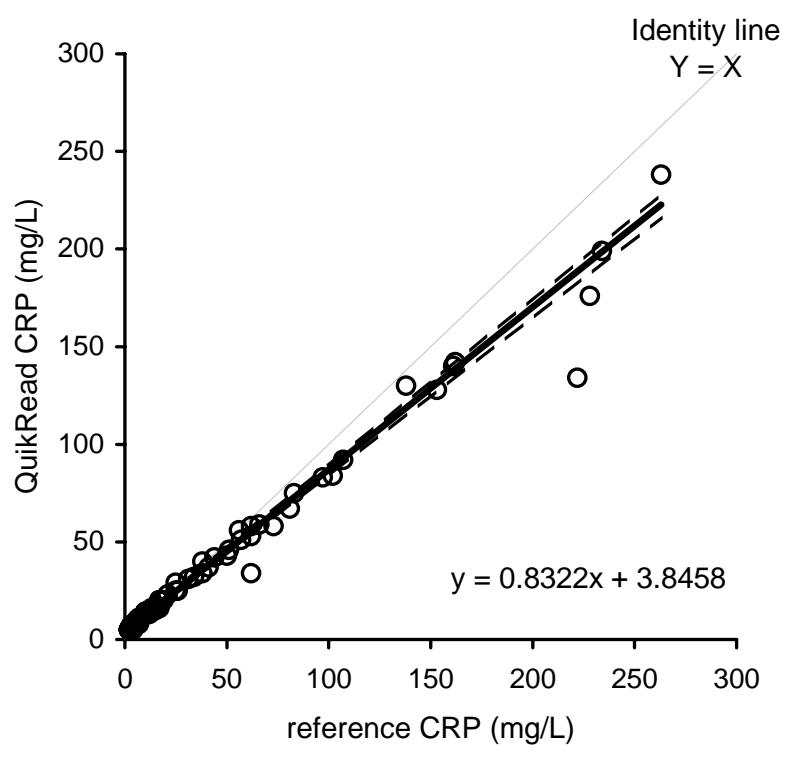


Figure 3

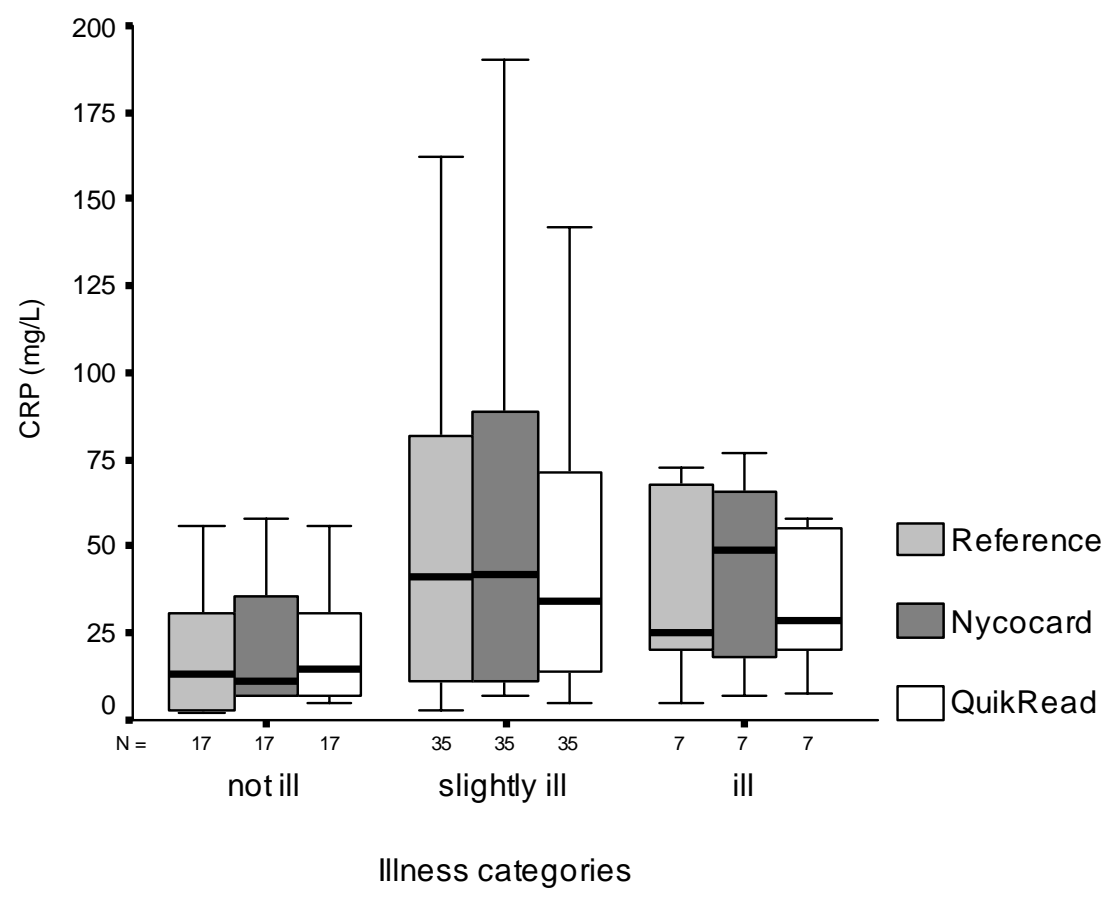

